\title{
Comparison of commercially available cytokeratin antibodies in normal and neoplastic adult epithelial and non-epithelial tissues
}

\author{
M J Goddard, B Wilson, J W Grant
}

\begin{abstract}
Five commercially available cytokeratin antibodies (lu-5, AE1/AE3, CAM 5.2, MFN116 and anti-cytokeratin 18) were used to stain a wide range of normal and neoplastic epithelial and non-epithelial tissues to assess their potential value in diagnostic histopathology. All five showed good specificity, with some cross-reactivity in smooth muscle cells. The wider reactivity of AE1/AE3, lu-5, and MFN 116, which includes cytokeratins 8,18 (Moll's catalogue) expressed in simple epithelia and their tumours, as well as cytokeratins expressed in complex stratified squamous epithelia, permits identification of a wider range of epithelial derived tumours.

This wider spectrum of reactivity may allow these antibodies to be used in a diagnostic panel for the identification of poorly differentiated tumours.
\end{abstract}

Immunohistochemistry has become increasingly important in identifying tumours which cannot be readily classified on morphological grounds. ${ }^{1-4}$

Cytokeratins occur in most normal epithelial tissues and antibodies against them have been used to characterise a wide variety of epithelial tumours. For routine histopathological diagnostic use, it is essential to use an antibody which recognises an antigen on the cytokeratin molecule which survives routine tissue fixation and embedding procedures. A cytokeratin antibody that can identify all epithelial types must react with the cytokeratins found in simple epithelia $(8,18$, 19-Moll's catalogue) as well as these found in complex stratified squamous epithelia $(1,4$, $5,6,10,11,13,14$ predominantly Moll's catalogue). Several monoclonal antibodies are now commercially available for this purpose. Of these, CAM 5.2 (Becton-Dickinson) and AE1/AE3 (ICN Biomedicals Ltd) have become the most widely used. More recently available cytokeratin antibodies have included lu-5 (Hoffman-La Roche), MFN 116 (Dako) and anti-cytokeratin 18 (Sigma).

CAM $5 \cdot 2$ is a murine monoclonal antibody raised by Makin et al in $1984,{ }^{5}$ against the colonic carcinoma cell line HT29. It is an IgG2a immunoglobulin which recognises the low molecular weight cytokeratins 8,18 , and 19 in Moll's Catalogue. ${ }^{6}$
AE1/AE3 is a mixture of two monoclonal antibodies, raised against human epidermal keratins. $^{7}$ AE1 recognises most of the acidic (type I) cytokeratins, while AE3 recognises all known basic (type II) cytokeratins. ${ }^{8}$ This combination shows broad reactivity and is claimed to stain almost all epithelia and their neoplasms. ${ }^{9}$

lu-5 recognises an intra-cytoplasmic formaldehyde resistant epitope which is located on the surface of cytokeratins but not on other cytoskeletal filaments. ${ }^{10}$ The epitope is not reactive after sodium dodecyl sulphate polyacrylamide gel electrophoresis, but can be identified in reconstituted purified proteins, suggesting that it is conformation dependent. The epitope is present on most cytokeratin polypeptides of both the acidic (type I) and basic (type II) subfamilies. This IgG antibody was raised by von Overbeck et al in $1985^{11}$ by intra-peritoneal immunisation of mice with the lung cancer cell lines A549 and A2181 (National Cancer Institute, Bethesda).

MFN 116 is a monoclonal antibody raised against MCF-7 cells in mice. As yet it is poorly characterised but immunoblotting has shown reactivity against cytokeratins 10, 17 and 18 (Specification sheets for MFN 116, Dakopatts).

Monoclonal anti-cytokeratin peptide 18 is a mouse monoclonal IgGl antibody which recognised the KS-B172 epitope in cells, and which reacts with a wide variety of simple epithelia. $^{12}$

Currently available data do not permit ready comparison of the relative advantages and disadvantages of these cytokeratin antibodies. We therefore analysed the staining of a wide range of normal and neoplastic epithelial and non-epithelial tissues with these cytokeratin antibodies.

\section{Methods}

Formalin fixed, paraffin wax embedded sections of normal and neoplastic tissue were obtained from the files of Addenbrooke's Hospital, Cambridge. Sections $(5 \mu \mathrm{m})$ were stained using the five antibodies listed (table 1). Staining was performed using the streptavidin-biotin method. Endogenous peroxidase activity was inhibited using $0.5 \%$ hydrogen peroxide for 10 minutes. The sections were predigested with $0.1 \%$ trypsin solution at $37^{\circ} \mathrm{C}$ for 10 minutes.

Background staining was reduced by the 
Table 3 Staining of epithelial tumours

\begin{tabular}{llllll}
\hline Carcinoma & \multicolumn{2}{l}{ CAM $5 \cdot 2$} & AE1/AE3 & lu-5 & \multicolumn{2}{l}{ MFN 116 Anti-cytokeratin-18 } \\
\hline Colorectal & $4 / 4$ & $4 / 4$ & $4 / 4$ & $4 / 4$ & $4 / 4$ \\
Gastric & $3 / 3$ & $3 / 3$ & $3 / 3$ & $3 / 3$ & $3 / 3$ \\
Breast & $4 / 4$ & $4 / 4$ & $4 / 4$ & $4 / 4$ & $4 / 4$ \\
Prostatic & $3 / 3$ & $3 / 3$ & $3 / 3$ & $3 / 3$ & $3 / 3$ \\
Renal cell & $3 / 3$ & $3 / 3$ & $3 / 3$ & $3 / 3$ & $3 / 3$ \\
Hepatocellular & $3 / 4$ & $2 / 4$ & $4 / 4$ & $3 / 4$ & $3 / 4$ \\
Transitional cell & $3 / 3$ & $3 / 3$ & $3 / 3$ & $3 / 3$ & $3 / 3(\mathrm{~A})$ \\
Carcinoid of appendix & $2 / 3$ & $2 / 3$ & $2 / 3$ & $2 / 3$ & $1 / 3$ \\
Teratoma-epithelial elements & $2 / 2$ & $2 / 2$ & $2 / 2$ & $2 / 2$ & $2 / 2$ \\
(well differentiated) & & & & & \\
Pleomorphic adenoma & $2 / 2$ & $2 / 2$ & $2 / 2$ & $2 / 2$ & $0 / 2$ \\
(epithelial elements) & & & & & \\
Squamous cell carcinoma & & & & & \\
$\quad$ Epidermis & $5 / 6$ & $6 / 6$ & $6 / 6$ & $6 / 6$ & $0 / 6$ \\
Cervix & $1 / 3$ & $3 / 3$ & $3 / 3$ & $3 / 3$ & $0 / 3$ \\
Bronchus & $2 / 5$ & $4 / 5$ & $4 / 5$ & $5 / 5$ & $0 / 5$ \\
\hline
\end{tabular}

(A) superficial layers of transitional cell epithelium.

routine use for several years and have become a "gold standard" against which newer arrivals will be judged. In this study we compared the staining of CAM $5 \cdot 2$ (Becton Dickinson) and AE1/AE3 (ICN Biomedicals) with the newer antibodies lu-5 (Hoffman-La Roche), MFN 116 (Dako) and anti-cytokeratin 18 (Sigma). All are suitable for use on formalin fixed, routinely processed, paraffin wax embedded material.

The detection of cytokeratin intermediate filaments is widely used to identify tumours of epithelial origin. Alternative markers of epithelial differentiation such as epithelial membrane antigen (EMA) or human milk fat globule 1 and 2 (HMFG 1 and 2) are also used. Often a cytokeratin and epithelial membrane antibody are used together in a diagnostic panel.

Epithelial membrane markers, although widely expressed in normal and neoplastic epithelial tissues, ${ }^{13} 1617$ have limitations in the range of tissues stained, and results in increasingly anaplastic tumours become unpredictable. ${ }^{14}$ Expression is also not restricted to epithelial cells. ${ }^{15}$

In a first line panel of antibodies, designed to establish the nature of a tumour, a marker of epithelial differentiation needs to show high degrees of sensitivity and specificity. The three monoclonal antibodies AE1/AE3, lu-5, and MFN 116 show a higher degree of sensitivity than CAM 5.2 and anti-cytokeratin 18 because they all recognise both the cytokeratins $(8,18)$, found in simple epithelia, as well as those expressed in stratified squamous epithelia. In the original study describing CAM $5 \cdot 2,{ }^{5}$ Makin et al showed positive staining of all nine of the squamous carcinomas to which the antibody was applied. In our current study, CAM 5·2 stained only eight of the 14 cases. This dis-

Table 4 Staining of non-epithelial tumours

\begin{tabular}{llllll}
\hline & CAM 5.2 & AE1/AE3 & lu-5 & \multicolumn{2}{l}{ MFN 116 Cytokeratin-18 } \\
\hline Melanoma & $0 / 7$ & $0 / 7$ & $0 / 7$ & $0 / 7$ & $0 / 7$ \\
Lymphoma & $0 / 4$ & $0 / 4$ & $0 / 4$ & $0 / 4$ & $0 / 4$ \\
Malignant fibrous histiocytoma & $0 / 3$ & $0 / 3$ & $0 / 3$ & $0 / 3$ & $0 / 3$ \\
Leiomyoma & $0 / 6$ & $0 / 6$ & $0 / 6$ & $0 / 6$ & $0 / 6$ \\
Leiomyosarcoma & $1 / 6$ & $2 / 6$ & $1 / 6$ & $1 / 6$ & $0 / 6$ \\
Liposarcoma & $0 / 3$ & $0 / 3$ & $0 / 3$ & $0 / 3$ & $0 / 3$ \\
Chondrosarcoma & $0 / 6$ & $0 / 6$ & $0 / 6$ & $0 / 6$ & $0 / 6$ \\
Ewing's sarcoma & $0 / 5$ & $0 / 5$ & $0 / 5$ & $0 / 5$ & $0 / 5$ \\
\hline
\end{tabular}

crepancy may be explained by the well documented changes in the pattern of expression of cytokeratins in tumours. ${ }^{18}$ In a proportion of squamous carcinomas there is presumably a change in the expression of specialised cytokeratins normally found in squamous epithelium to those found in simple epithelia. Cytokeratin 18 has been found in some squamous cell carcinomas and may be associated with invasion. These changes, however, are not universally seen. ${ }^{19}$

The only tumour not stained by the panel of antibodies was one case of carcinoid tumour of the appendix. Non-expression of cytokeratins in unequivocal carcinomas has been reported previously, ${ }^{2021}$ most commonly in renal cell carcinomas. In this study all three cases of renal carcinoma expressed cytokeratins.

All five antibodies seem to be highly specific for epithelial tissues, with the notable exception of normal and neoplastic smooth muscle cells. Staining of smooth muscle is well documented..$^{22-24}$ Although in this study only a small proportion of smooth muscle tumours expressed cytokeratins, other studies have shown an $80-100 \%$ expression. ${ }^{23}{ }^{24}$ It has been suggested that the source of this reactivity is a cross-reaction with nuclear lamins, a nuclear associated protein, with a keratin-like amino acid composition. ${ }^{25}$ The pattern of staining is cytoplasmic rather than nuclear as might be expected if there was cross-reaction with nuclear lamins. Cytokeratins, however, have also been isolated from smooth muscle cells by two dimensional gel electrophoresis. ${ }^{26}$

Cytokeratin antibodies which show a reactivity to a wide spectrum of cytokeratins have an advantage over those with a more restricted reactivity, in that they recognise a wider range of epithelial derived tumours. CAM $5 \cdot 2$ retains a good reactivity, although it may fail to recognise squamous carcinomas expressing high molecular weight cytokeratins. AE1/AE3 and $1 \mathrm{u}-5$ are well characterised and produce good reproducible results. MFN 116, while showing a similar reactivity, is less well characterised, and in our hands produced less consistent results.

Anti-cytokeratin 18, overall, produces less consistent and less intense staining patterns. As cytokeratins are obligate hetero polymers, the weaker staining observed may in part reflect less available epitope for antibody interaction, or may be due to lower affinity of the antibody. It is limited in its usefulness in a diagnostic panel because of its monospecific nature. It may, however, prove a useful tool in showing changes in cytokeratin expression in tumours when compared with normal epithelia.

We have found that the optimal working dilution of the supplied antibodies is greatest with lu-5 and MFN 116 which may make them more cost effective in routine use.

Our study has examined the staining patterns of normal and neoplastic tissues with a number of commercially available cytokeratin antibodies. The tumours studied have all been identifiable on morphological grounds and would not have posed diagnostic problems. The value of immunohistochemistry is in the 
identification of those tumours, such as small and large cell anaplastic and spindle cell carcinomas, whose epithelial nature is not apparent morphologically. In this paper we established the spectrum of reactivity and specificity of these monoclonal antibodies. Further work is being undertaken to establish the value of these antibodies in tumours that are not classifiable on morphological grounds alone.

1 Gatter KC, Abdulaziz Z, Beverely P, et al. Use of monoclonal antibodies for the histopathological diagnosis of human malignancy. J Clin Pathol 1982;35:1253-67.

2 Lauder I, Holland D, Mason DY, Gowland G, Cunliffe WJ. Identification of large cell undifferentiated tumours in lymph nodes using leucocyte common and keratin lymph nodes using leucocyte com
antibodies. Histopathol 1982;8:259-72.

3 Gatter KC, Alcock C, Heryet A, et al. The differential diagnosis of routinely processed anaplastic tumours using

4 Poston RN, Sidhu YS. Diagnosing tumours on routine surgical sections by immunohistochemistry: Use of cytokeratin, common leucocyte and other markers. J Clin Pathol 1986;39:514-23.

5 Makin C, Bobrow L, Bodmer W. Monoclonal antibody for use in routine histopathology. J Clin Pathol 1984;37: 975-83.

6 Moll R, Franke W, Schiller D, Geiger B, Krepher R. The catalogue of human cytokeratins: patterns of expression in normal epithelia, tumours and cultured cells. Cell 1982;31:11-24.

7 Woodcock-Mitchell J, Eichner R, Nelson WG, Sun T-T Immunolocalisation of keratin polypeptides in human epidermis usin

8 Tseng SCG, Jarvinen M, Nelson WG, Twang J-W, Woodcock-Mitchell J, Sen T-T. Correlation of specific keratin with different types of epithelial differentiation Monoclonal antibody studies. Cell 1982;30:361-72.

9 Spagnolo DV, Michie SA, Crabtree GS, Warnke RA, Ronse RV. Monoclonal anti-keratin (AE1) reactivity in routinely processed tissue from 166 human neoplasms. Am J Clin Pathol 1983;84:697-704.

10 Franke W, Winter S, von Overbeck J, Gudat F, Heitz P, Stahli C. Identification of the conserved confirmation dependent cytokeratin epitope recognised by monoclonal antibody. lu-5 Virchows Arch (Cell Pathol) 1987;411: antibody.

11 von Overbeck J, Stahli C, Gudat F, et al. Immunohistochemical characterisation of an anti-epithelial monoclonal antibody (MAb lu-5) Virchows Arch (Cell Pathol) 1985;407:1-12.
12 Levy R, Czernobilsky B, Geiger B. Subtyping of epithelial cells of normal and metaplastic uterine cervi using polypeptide-specific cytokeratin antibodies. Differentiation 1988;39:185-96.

13 Heydermann E, Steele K, Ormerod M. A new antigen on the epithelial membrane: its immunoperoxidase localisation in normal and neoplastic tissue. J Clin Pathol 1979;32: 35-9.

14 Sloane JP, Ormerod MG. Distribution of epithelial membrane antigen in normal and neoplastic tissues and its membrane antigen in normal and neoplastic tissues and its 47:1786-95.

15 Delsol G, Gatter KC, Stein H, et al. Human lymphoid cells express epithelial membrane antigen-Implications for diagnosis of human neoplasms. Lancet 1984;ii:1124-8.

16 Taylor-Papdimitriou J, Petersen J, Arklie J, Burchell J, Ceriani R, Bodmer W. Monoclonal antibodies to epithelium specific components of the human milk fat globule membrane; production and reaction with cells in culture. Int J Cancer 1981;28:17-21.

17 Arklie J, Taylor-Papadimitriou J, Bodmer W, Egan M Millis R. Differentiation antigens expressed by epithelial cells in lactating breast are also detectable in breast cancers. Int J Cancer 1981;28:23-9.

18 Garin-Chesa P Retig WJ, Melamed MR. Expression of cytokeratins in normal and neoplastic colonic epithelial cytokeratins in normal and neoplastic colonic epithelial cells. Implications for cellular differentiation

19 Huszer M, Gigi-Leitner O, Moll R, Frank W, George B. Monoclonal antibodies to various acidic (type 1) cytokeratins of stratified epithelia. Selective markers for stratification and squamous cell carcinoma. Differentiation 1986;31:141-53.

20 Herman CJ, Moester O, Kant A, Huysman A, Voojs GP, Ramaetas FG. Is renal cell (Grawitz) tumour a Carcinosarcoma? Virchows Arch (Cell Pathol) 1983;44:77-83.

21 Leader M, Patel J, Matin C, Henry K An analysis of sensitivity and specificity of the cytokeratin (CAM 5.2) for epithelial tumours. Results of a study of 203 sarcomas, 50 carcinomas and 28 malignant melanomas. Histopathol carcinomas and

22 Bronn D, Theaker J, Banks P, Gatter K, Mason D. Cytokeratin expression in smooth muscle and smooth muscle tumours. Histopathol 1987;11:477-86.

23 Norton AJ, Thomas JA, Isaacson P. Cytokeratin specific antibodies are reactive with tumours of smooth muscle derivation. An immunocytochemical and biochemical study using antibodies to intermediate filament cytoskeletal protein. Histopathol 1987;11:487-99.

24 Ramaekers F, Pruszcynski M, Smedts F. Cytokeratins in smooth muscle cells and smooth muscle tumours. Histopathol 1988;12:558-61.

25 Goldman A, Maul G, Steiner P, Young H, Goldman R. Keratin-like proteins that co-isolate with intermediate
filaments of BHK-21 cells are nuclear lamins. Proc Natl Acad Sci USA 1986;83:3839-43.

26 Van Mijen G, Ruiter D, Warnarr S. Double and triple expression of intermediate filaments in human foetal and non-malignant adult tissues. Lab Invest 1987;57:259-69. 